\title{
Comparison of the health status of exclusively breastfeeding infants and newborns receiving sugar water along with breast milk
}

\author{
Comparación del estado de salud de recién nacidos \\ alimentados exclusivamente con leche humana vs los que la \\ reciben junto con agua azucarada
}

\author{
Hassan Boskabadi, ${ }^{1}$ Gholamali Maamouri, ${ }^{1}$ Fatemeh Bagheri, ${ }^{2}$ Maryam Zakerihamidi ${ }^{3}$
}

\begin{abstract}
OBJECTIVE: To compare newborns fed exclusively on human milk with those fed sugar water along with the mother's milk.

MATERIALS AND METHODS: Cross-sectional study conducted on selected newborns through sampling available at the clinic and neonatal ward and the emergency department of Ghaem Hospital in Mashhad, Iran, during 2014-2018. The data collection tool was a questionnaire developed by researchers that included laboratory data, maternal information, and neonatal characteristics. The data was analyzed with $\mathrm{t}$ for Student and $\chi^{2}$. RESULTS: Of 445 neonates, 324 (72.8\%) were exclusively breastfed, and 121 (27.2\%) were fed breast milk along with sugar water. A significant difference was found between the two groups in terms of maternal age $(p=0.001)$, breastfeeding frequency $(p=0.002)$, feeding duration $(p=0.013)$, urination frequency $(p=0.001)$, weight on admission $(p=0.001)$, daily weight loss $(p=0.001)$, daily weight loss percentage $(p$ $=0.001)$, and serum levels of sodium $(p=0.001)$, potassium $(p=0.019)$, urea $(p=$ $0.001)$, creatinine $(p=0.001)$, and platelet $(p=0.001)$. Moreover, lethargy, irritability, mucosal dryness, hyperthermia, apnea, loss of consciousness, mother's breast problems, and inappropriate breastfeeding position were more common in newborns who were fed sugar water along with breast milk, compared to exclusively breastfed newborns. CONCLUSION: All indications are that nutritional and maternal breast problems, laboratory abnormalities and neonatal complications increased when sugar water was added to human milk.
\end{abstract}

KEYWORDS: Breastfeeding, Sugar water, Neonate, Breast problems, Neonatal complications

Resumen

OBJETIVO: Comparar a los recién nacidos alimentados exclusivamente con leche humana con los que reciben agua azucarada junto con la leche de la madre.

MATERIALES Y MÉTODOS: Estudio transversal efectuado en recién nacidos seleccionados mediante un muestreo disponible en la clínica y sala neonatales y el departamento de Urgencias del Hospital Ghaem en Mashhad, Irán, durante 2014-2018. La herramienta de recopilación de datos fue un cuestionario elaborado por los investigadores que incluía datos de laboratorio, información de la madre y características neonatales. Los datos se analizaron con t de Student y $\chi^{2}$.

RESULTADOS: De 445 recién nacidos, 324 (72.8\%) solo fueron amamantados y 121 $(27.2 \%)$ se alimentaron con leche humana, más agua azucarada. Se encontró una diferencia significativa entre los dos grupos en términos de edad materna $(p=0.001)$, frecuencia de lactancia $(p=0.002)$, duración de la alimentación $(p=0.013)$, frecuencia de micción $(p=0.001)$, peso al ingreso $(p=0.001)$, pérdida de peso diaria $(p=$ $0.001)$, porcentaje de pérdida de peso diaria $(p=0.001)$ y concentraciones séricas de sodio $(p=0.001)$, potasio $(p=0.019)$, urea $(p=0.001)$, creatinina $(p=0.001)$ y

\footnotetext{
Professor, Department of Pediatrics, Faculty of Medicine, Mashhad University of Medical Science, Mashhad, Iran 2 Department of Nursing, School of Medical Sciences, Mashhad Branch, Islamic Azad University, Mashhad, Iran ${ }^{3}$ Assistant Professorin Reproductive Health, Department of Midwifery, School of Medical Sciences, Tonekabon Branch, Islamic Azad University, Tonekabon, Iran.
}

Received: October 72018

Accepted: 20 de agosto 2020

Correspondence

Maryam Zakerihamidi

maryamzakerihamidi@yahoo.co.nz

This article should be cited as: Boskabadi H, Maamouri G, Bagheri F, Zakerihamidi M. Comparison of the health status of exclusively breastfeeding infants and newborns receiving sugar water along with breast milk. Acta Pediatr Mex 2020; 41(5): 199-207. DOI: 
plaquetas $(p=0.001)$. Además, el letargo, la irritabilidad, la sequedad de las mucosas, la hipertermia, la apnea, la pérdida del conocimiento, los problemas mamarios de la madre y la posición inadecuada para amamantar fueron más comunes en los recién nacidos alimentados con agua azucarada junto con leche humana versus los recién nacidos solo amamantados.

CONCLUSIÓN: Todo indica que los problemas nutricionales, de las mamas de la madre, las anomalías de laboratorio y las complicaciones neonatales se incrementaron cuando a la leche humana se agregó agua azucarada.

PALABRAS CLAVE: Lactancia materna; agua azucarada; neonato; problemas mamarios; complicaciones neonatales.

\section{BACKGROUND}

According to the World Health Organization (WHO), infants who are fed breast milk, without any liquid or semi-solid foods, are considered as exclusively breastfed, while infants who receive supplementary water and water-based drinks, such as fruit juices, sugar water, water, and herbal teas, are considered as predominantly breastfed. ${ }^{1}$ WHO highly recommended exclusive breastfeeding to increase the survival of children and reduce the incidence of pediatric diseases around the world. This organization also emphasizes that all countries must promote and follow-up exclusive breastfeeding programs for children up to six months of age. ${ }^{2}$

In Iran, possible causes of reduced milk intake within the first days of newborn's life may be the lack of proper maternal education about breastfeeding problems within the first days of infant's life, early discharge of mothers from hospital before lactation stabilization, high prevalence of cesarean section, mother's breast problems, lack of proper follow-up after discharge, and use of traditional supplements, such as manna and sugar water. ${ }^{3}$ Use of water and traditional supplements (e.g., manna, flixweed, sugar water, and water) as sedative agents is common in the Iranian culture due to some family beliefs. For instance, it is believed that these supplements can decrease the occurrence of jaundice. ${ }^{4}$
Reduction of the rate and duration of exclusive breastfeeding, which is considered a serious health problem, especially in developing countries, can lead to a two- or three-fold increase in malnutrition, infection, and mortality. ${ }^{5}$ Infants who are not breastfed are at a high risk of otitis media, diarrhea, lower respiratory tract infections, obesity, diabetes, leukemia, sudden infant death syndrome, and necrotizing enterocolitis. In addition, type 2 diabetes, myocardial infarction, and breast or ovarian cancer are more common in mothers who do not experience breastfeeding. ${ }^{6}$

Evidence shows that breastfeeding improves the infant's health and has many benefits for both the mother and the child. Therefore, many efforts have been made by governments, pediatricians, obstetricians, and WHO to promote breastfeeding. Breastfeeding counseling is an essential part of pregnancy care for pregnant women. Also, early diagnosis of breastfeeding disorders can be achieved by taking measures, such as frequent weighing of infants for detecting pathological weight loss in the first week of life. ${ }^{?}$

The objective of this study was to compare newborns fed exclusively on human milk with those fed sugar water along with the mother's milk.

\section{MATERIALS AND METHODS}

This cross-sectional study was conducted on 445 neonates, who were selected via avail- 
able sampling among neonates admitted to the neonatal clinic, neonatal ward, and emergency department of Ghaem Hospital in Mashhad, Iran, during 2014-2018. The study sample included $324(72.8 \%)$ exclusively breastfed infants and $121(27.2 \%)$ newborns, who received breast milk along with sugar water (once a day at least).

This study was approved by the Vice Chancellor of the Ethics Committee of Mashhad University of Medical Sciences. The parents' consent was also obtained before including the neonates in the study. Healthy newborns, who were discharged from the midwifery department and were referred to the neonatal clinic or emergency department, were included in the study. All of this neonate required an initial assessment or routine care, including breastfeeding, warmth, cord care, and hygiene. On the other hand, newborns with asphyxia, gestational age less than 35 weeks, congenital anomalies, and neonatal jaundice requiring treatment were excluded from the study. Neonates who were admitted to the hospital from birth were also excluded.

A checklist was completed for each newborn in the two groups. The infant's information in this checklist included age, birth weight, duration of hospitalization, chief complaint, APGAR score, duration of breastfeeding, frequency of defecation, weight on admission, frequency of breastfeeding, frequency of urination, duration of feeding, daily weight loss, percentage of daily weight loss, sex, lethargy, irritability, mucosal dryness, fontanelle status, hyperthermia, seizure, apnea, decreased consciousness, and jaundice. On the other hand, the maternal data included maternal age, parity, maternal weight, maternal hospitalization duration, breast problems, mode of delivery, breastfeeding position, delayed breastfeeding, and pregnancy problems. In addition, the laboratory findings included $\mathrm{pH}$ and serum levels of bilirubin, platelet, hematocrit, glucose, sodium, urea, and creatinine. The paraclinical examinations were requested by the physician, and we only recorded the test results without any interference.

Data were analyzed using t-test and $\chi^{2}$ test in SPSS version 23. First, the results were presented in tables and statistical charts, and then, the two groups of newborns were compared using $\chi^{2}$ and $\mathrm{t}$ test. The significance level was considered to be $p \leq 0.05$.

\section{RESULTS}

In this cross-sectional study, 445 out of 471 infants were selected and enrolled in the study. Newborns receiving water and traditional supplements, such as manna and flixweed $(n=16)$, as well as infants with congenital anomalies ( $\mathrm{n}$ $=2$ ) and neonatal jaundice requiring treatment $(n=8)$, were excluded from the study. Finally, two groups of infants, including $324(72.8 \%)$ exclusively breastfed newborns and 121 (27.2\%) newborns receiving breast milk plus sugar water, were compared.

No significant difference was found between the two groups in terms of the infant's age $(p=0.338)$, birth weight $(p=0.362)$, length of hospitalization $(p=0.202)$, APGAR score $(p=0.918)$, defecation frequency $(p=0.981)$, parity $(p=0.508)$, maternal weight $(p=0.138)$, maternal hospitalization $(p=$ $0.330)$, total bilirubin level $(p=0.136)$, hematocrit level $(p=0.060), \mathrm{pH}(\mathrm{p}=0.440)$, and blood glucose $(p=0.996)$. Conversely, a significant difference was found between the two groups regarding weight on admission $(p=0.000)$, frequency of breastfeeding $(p=0.002)$, duration of feeding ( $p=0.013)$, daily weight loss $(p=0.000)$, daily weight loss percentage $(p=0.000)$, urinary frequency $(p=0.000)$, maternal age $(p=0.001)$, 
and levels of sodium $(p=0.001)$, potassium $(p=$ $0.019)$, urea $(p=0.000)$, creatinine $(p=0.000)$, and platelet $(p=0.000)$. In other words, in the group of predominantly breastfed infants, the serum levels of sodium, potassium, urea, and creatinine, daily weight loss, and daily weight loss percentage were higher than the exclusively breastfed group. On the other hand, weight on admission, frequency of breastfeeding, frequency of urination, maternal age, platelet count, and duration of feeding were lower in the exclusively breastfed group. Table 1

There was no significant relationship between the mode of feeding and pregnancy problems $(p=0.130)$, delayed breastfeeding $(p=0.323)$, mode of delivery $(p=0.150)$, and infant's sex $(p=0.817)$. However, there was a significant difference between the groups in terms of breast problems $(p=0.003)$. Inappropriate breastfeed-

Table1. Comparison of mean of variables between exclusively breastfeeding infants and neonates consuming breastfeeding plus Sugar water.

\begin{tabular}{|c|c|c|c|}
\hline $\begin{array}{l}\text { Groups } \\
\text { Variables }\end{array}$ & $\begin{array}{c}\text { Exclusively } \\
\text { breastfeeding infants } \\
324(72.8 \%)\end{array}$ & $\begin{array}{c}\text { Predominantly } \\
\text { breastfeeding infants } \\
121(27.2 \%)\end{array}$ & $\begin{array}{c}\text { Significance levels* } \\
\text { (T-test) }\end{array}$ \\
\hline Age (day) & $3.80 \pm 6.94$ & $4.27 \pm 7.34$ & 0.338 \\
\hline Birth weight (gr) & $457.95 \pm 3197.53$ & $458.12 \pm 3152.97$ & 0.362 \\
\hline Admission weight (gr) & $529.91 \pm 3143.08$ & $512.50 \pm 2816.44$ & 0.000 \\
\hline Daily weight loss (gr) & $62.25 \pm 18.57$ & $57.39 \pm 58.98$ & 0.000 \\
\hline Daily weight loss (percentage) & $1.90 \pm 0.55$ & $1.80 \pm 1.88$ & 0.000 \\
\hline Infant's hospitalization(day) & $2.08 \pm 2.87$ & $4.14 \pm 4.15$ & 0.202 \\
\hline APGAR score & $0.36 \pm 9.01$ & $0.45 \pm 9.02$ & 0.918 \\
\hline Lactation frequency & $2.27 \pm 9.58$ & $2.92 \pm 8.68$ & 0.002 \\
\hline Feeding duration (min) & $7.99 \pm 19.91$ & $12.71 \pm 10.60$ & 0.013 \\
\hline Urination frequency (Times/ day) & $1.57 \pm 5.34$ & $1.94 \pm 4.14$ & 0.000 \\
\hline Defecation frequency (Times/ day) & $2.05 \pm 3.82$ & $2.43 \pm 3.81$ & 0.981 \\
\hline Maternal age (year) & $5.87 \pm 27.51$ & $5.73 \pm 25.43$ & 0.001 \\
\hline Parity & $1.14 \pm 1.78$ & $0.94 \pm 1.68$ & 0.508 \\
\hline Maternal weight (kg) & $11.08 \pm 68.87$ & $11.85 \pm 66.41$ & 0.138 \\
\hline Mother's hospitalization (day) & $1.40 \pm 0.68$ & $0.81 \pm 1.50$ & 0.330 \\
\hline Sodium $(\mathrm{mEq} / \mathrm{L})$ & $9.29 \pm 145.10$ & $14.88 \pm 155.82$ & 0.000 \\
\hline Potassium (mEq/L) & $0.79 \pm 4.96$ & $0.91 \pm 5.22$ & 0.019 \\
\hline Urea (mg/dl) & $49.65 \pm 39.31$ & $110.69 \pm 94.77$ & 0.000 \\
\hline Creatinine (mg/dl) & $0.74 \pm 0.62$ & $1.91 \pm 1.54$ & 0.000 \\
\hline Total bilirubin (mg/dl) & $3.52 \pm 15.76$ & $3.89 \pm 14.97$ & 0.136 \\
\hline Hematocrit (percent) & $7.62 \pm 45.91$ & $9.53 \pm 48.66$ & 0.060 \\
\hline Platelet (per $\mu \mathrm{mL}$ ) & $98054.14 \pm 270070.17$ & $97505.13 \pm 172325.00$ & 0.000 \\
\hline $\mathrm{PH}$ & $0.10 \pm 7.35$ & $0.10 \pm 7.32$ & 0.440 \\
\hline Blood sugar (mg/dl) & $89.78 \pm 104.17$ & $90.00 \pm 104.10$ & 0.996 \\
\hline
\end{tabular}

*Values are based on standard deviation \pm mean 
ing position was more common in the group receiving additional sugar water $(p=0.000)$. The prevalence of lethargy, irritability, dryness of mucosa, depressed fontanelle, hyperthermia, seizure, apnea, and decreased consciousness were significantly higher in the group receiving breast milk plus sugar water $(p=0.000)$. Table 2

\section{DISCUSSION}

In the present study, the two groups of neonates were homogeneous in terms of age, birth weight, length of hospitalization, Apgar score, parity, maternal weight, maternal hospitalization duration, and total bilirubin, hematocrit, and blood sugar levels. In this study, about one-fourth of mothers fed their newborns sugar water besides breast milk. In this regard, a study from China reported that $26 \%$ of neonates born in the hospital were fed formula, water, or cow's milk as the initial feeding. ${ }^{8}$

The most common reasons for using such drinks were cultural beliefs (61\%) and grandmothers' recommendations (58.3\%). ${ }^{9}$ In some societies, use of supplementary water or water-based drinks are considered prior to breastfeeding during the first days of the newborn's life, based on the belief that colostrum has a low nutritional value, may cause thirst, and be harmful for the newborn. ${ }^{10}$ The results of a previous study showed that $13.8 \%$ of infants used water in the first month of life, $15.3 \%$ used a type of tea, and $17.8 \%$ used non-human milk. ${ }^{11}$

In a study by Mortazavi et al. (2015) conducted in Shahroud, Iran, consumption of sugar water, water, herbal tea, and formula was reported to be $10.1 \%, 3.6 \%, 52.2 \%$, and $8.6 \%$ in the first month of birth, respectively. ${ }^{12}$ However, the American Academy of Pediatrics and WHO have strongly advised not to use water, tea, or other liquids along with breast milk, because they do not have any nutritional value, and there is a high risk of contaminant or allergen transmission. In addition, consumption of these fluids reduces the infant's interest in the mother's breast, and consequently, decreases the frequency of breastfeeding. ${ }^{13}$

On the other hand, transmission of grandparents' beliefs to the next generation is of great importance in our society. Therefore, identifying and correcting subcultures using appropriate methods can play a key role in the promotion of community health. These beliefs are sometimes useful and sometimes problematic in the healthcare setting. For instance, keeping the baby in a warm place, which is strongly emphasized in our culture, helps the infant adapt to the outside temperature. However, extreme beliefs, such as traditional swaddling, can cause severe complications in infants, such as dehydration, seizure, or renal failure in the first days of life.

Another common belief in our society is the use of sugar water within the first days after birth as an alternative or a supplement to breast milk. The volume of milk is low in the first days of the newborn's life and gradually increases over time; therefore, families look for a substitute to breast milk due to concerns about their newborn. One of these substitutes is sugar water, which reduces the infant's appetite due to its high osmolality and lack of sterility, while fewer breast milk intakes can cause several difficulties for the infant. ${ }^{14}$

According to numerous studies, the prevalence of feeding sugar water along with breast milk ranges between 9.5 and $40 \% .^{14-1}$

In the present study, maternal age was lower in the group receiving sugar water along with breast milk, compared to the exclusively breastfed group. In a study by Giugliani (2017), use of water and/or herbal tea, besides breast milk, was 
associated with maternal age below 20 years. ${ }^{15}$ Overall, younger mothers without the experience of lactation may be influenced by their older relatives about using sugar water and herbal tea along with breast milk to prevent or treat infantile colic or jaundice. ${ }^{16}$ Primiparous and younger mothers are more likely to experience breast and lactation problems and are influenced by their relatives for using more non-milk supplements. ${ }^{17}$

Furthermore, in the present study, breast problems and inappropriate breastfeeding positions

Table 2. Comparison of neonatal variables in neonates fed by breastfeeding and neonates consuming lactation plus Sugar water

\begin{tabular}{|c|c|c|c|c|}
\hline Groups & Variables & $\begin{array}{c}\text { Exclusively } \\
\text { breastfeeding infants } \\
324(72.8 \%)\end{array}$ & $\begin{array}{c}\text { Predominantly } \\
\text { breastfeeding neonates } \\
121(27.2 \%)\end{array}$ & $\chi^{2}$ test* \\
\hline Sex & $\begin{array}{l}\text { Male } \\
\text { Female }\end{array}$ & $\begin{array}{l}173(55.10 \%) \\
141(44.90 \%)\end{array}$ & $\begin{array}{l}63(53.80 \%) \\
54(46.20 \%)\end{array}$ & 0.817 \\
\hline $\begin{array}{l}\text { Breast } \\
\text { problems }\end{array}$ & $\begin{array}{l}\text { No } \\
\text { Yes }\end{array}$ & $\begin{array}{c}249(76.90 \%) \\
75(23.10 \%)\end{array}$ & $\begin{array}{l}76(62.80 \%) \\
45(37.20 \%)\end{array}$ & 0.003 \\
\hline Type of delivery & $\begin{array}{l}\text { Natural } \\
\text { Cesarean }\end{array}$ & $\begin{array}{l}168(51.90 \%) \\
156(48.10 \%)\end{array}$ & $\begin{array}{l}72(59.50 \%) \\
49(40.50 \%)\end{array}$ & 0.150 \\
\hline Breastfeeding position & $\begin{array}{l}\text { Proper } \\
\text { Improper }\end{array}$ & $\begin{array}{c}195(89.00 \%) \\
24(11.00 \%)\end{array}$ & $\begin{array}{l}41(56.20 \%) \\
32(43.80 \%)\end{array}$ & 0.0001 \\
\hline Delay in Breastfeeding & $\begin{array}{l}\text { Yes } \\
\text { No }\end{array}$ & $\begin{array}{c}2(2.90 \%) \\
67(97.10 \%)\end{array}$ & $\begin{array}{c}3(6.80 \%) \\
41(93.20 \%)\end{array}$ & 0.323 \\
\hline Pregnancy problems & $\begin{array}{l}\text { Yes } \\
\text { No }\end{array}$ & $\begin{array}{c}28(12.40 \%) \\
197(87.60 \%)\end{array}$ & $\begin{array}{l}19(18.80 \%) \\
82(81.20 \%)\end{array}$ & 0.130 \\
\hline Chief complaint & $\begin{array}{l}\text { Routine care } \\
\text { Jaundice } \\
\text { Lethargy } \\
\text { Irritability } \\
\text { Fever } \\
\text { Seizure } \\
\text { Loss of consciousness } \\
\text { Poor feeding }\end{array}$ & $\begin{array}{c}84(25.90 \%) \\
185(57.10 \%) \\
0(0) \\
28(8.60 \%) \\
27(8.30 \%) \\
0(0) \\
0(0) \\
0(0)\end{array}$ & $\begin{array}{c}10(8.30 \%) \\
37(30.60 \%) \\
8(6.60 \%) \\
8(6.60 \%) \\
28(23.10 \%) \\
11(9.10 \%) \\
1(0.80 \%) \\
18(14.90 \%)\end{array}$ & 0.0001 \\
\hline Lethargy & $\begin{array}{l}\text { No } \\
\text { Yes }\end{array}$ & $\begin{array}{c}306(94.40 \%) \\
18(5.60 \%)\end{array}$ & $\begin{array}{l}89(73.60 \%) \\
32(26.40 \%)\end{array}$ & 0.0001 \\
\hline Irritability & $\begin{array}{l}\text { No } \\
\text { Yes }\end{array}$ & $\begin{array}{c}277(85.50 \%) \\
47(14.50 \%)\end{array}$ & $\begin{array}{l}82(67.80 \%) \\
39(32.20 \%)\end{array}$ & 0.0001 \\
\hline Mucosal dryness & $\begin{array}{l}\text { No } \\
\text { Yes }\end{array}$ & $\begin{array}{c}300(92.60 \%) \\
24(7.40 \%)\end{array}$ & $\begin{array}{l}84(69.40 \%) \\
37(30.60 \%)\end{array}$ & 0.0001 \\
\hline Status of the fontanels & $\begin{array}{l}\text { Normal } \\
\text { Inverted } \\
\text { Bulging }\end{array}$ & $\begin{array}{c}316(97.50 \%) \\
6(1.90 \%) \\
2(0.60 \%)\end{array}$ & $\begin{array}{c}110(90.90 \%) \\
11(9.10 \%) \\
0(0)\end{array}$ & 0.001 \\
\hline Hyperthermia & $\begin{array}{l}\text { No } \\
\text { Yes }\end{array}$ & $\begin{array}{c}292(90.10 \%) \\
32(9.90 \%)\end{array}$ & $\begin{array}{l}71(58.70 \%) \\
50(41.30 \%)\end{array}$ & 0.0001 \\
\hline Seizure & $\begin{array}{l}\text { No } \\
\text { Yes }\end{array}$ & $\begin{array}{c}324(100 \%) \\
0(0)\end{array}$ & $\begin{array}{c}107(88.40 \%) \\
14(11.60 \%)\end{array}$ & 0.0001 \\
\hline Apnea & $\begin{array}{l}\text { No } \\
\text { Yes }\end{array}$ & $\begin{array}{c}324(100 \%) \\
0(0)\end{array}$ & $\begin{array}{c}112(92.60 \%) \\
9(7.40 \%)\end{array}$ & 0.0001 \\
\hline Unconsciousness & $\begin{array}{l}\text { No } \\
\text { Yes }\end{array}$ & $\begin{array}{c}324(100 \%) \\
0(0)\end{array}$ & $\begin{array}{c}114(94.20 \%) \\
7(5.30 \%)\end{array}$ & 0.0001 \\
\hline
\end{tabular}


were more common among neonates receiving breast milk plus sugar water, compared to the exclusively breastfed group. In another study, a common breast problem was poor let-down reflex, and inappropriate breastfeeding positions were more common among mothers, who used traditional supplements for their infants. ${ }^{4}$ It should be noted that lactation problems can shorten the duration of breastfeeding. ${ }^{18}$ Therefore, these problems should be identified and resolved on the first day after delivery.

Since breastfeeding problems are one of the predictors of lactation disruption, the importance of lactation counseling is highlighted during pregnancy and delivery. It is uncertain whether breast problems are related to the use of sugar water or vice versa. However, these two factors probably have negative effects on one another; in other words, consumption of sugar water reduces the discharge of breast and exacerbates related problems. On the other hand, breast problems make breastfeeding harder and force the mother to use other supplements, such as sugar water.

In the current study, the duration and frequency of breastfeeding were lower in the group receiving breast milk plus sugar water, compared to the exclusively breastfed group. Another study revealed that use of pacifier, sugar water, and complementary foods along with breast milk had negative effects on the breastfeeding duration in the first six months of life..$^{19} \mathrm{Also}$, the results of another study showed that consumption of formula together with supplementary foods significantly affected the early interruption of breastfeeding. ${ }^{20}$ In another study, use of a type of milk other than breast milk had negative effects on lactation. ${ }^{15}$

Rasenack et al. (2012) showed that use of sugar water or formula supplements on the first day of life could have negative effects on the duration of breastfeeding after the age of six months. ${ }^{21}$ Generally, infants try hard to maintain breastfeeding in the first days of life, and repeated sucking leads to increases the milk volume within 3-5 days. If sugar water or similar supplements are consumed, the infant's appetite decreases. Also, the newborn's interest in breastfeeding reduces or completely goes away shortly after the start of feeding.

In our study, the percentage of daily weight loss in infants consuming additional sugar water was nearly four times higher than newborns with exclusive breastfeeding. Similarly, in a study by Martin-Calama et al, infants who were exclusively breastfed were compared with those who received breast milk plus sugar water. Their findings showed that weight loss was higher in infants receiving additional sugar water in the first 48 hours of life. ${ }^{22}$ Sugar water, due to its sweet taste, may reduce the infant's appetite and cause diarrhea, which can lead to weight loss or inappropriate weight gain. Overall, all of these factors can exacerbate weight loss and prolong the newborn's return to birth weight. ${ }^{8}$

In our study, similar to a study by Martin-Calama et al, the frequency of hyperthermia (temperature above $37.5^{\circ} \mathrm{C}$ ) was higher in the group of newborns who consumed breast milk plus sugar water. ${ }^{22}$ The main cause of neonatal hyperthermia is excess wear or reduced milk intake. As sugar water reduces the neonate's appetite and breastfeeding frequency, it can result in hyperthermia and weight loss. ${ }^{23}$

In the current study, the frequency of urination in the group of newborns who consumed breast milk plus sugar water was lower than the group of exclusively breastfed neonates. In another study, the frequency of urination in 59\% of exclusively breastfed neonates was eight times (or more) per 
day, while in $14.5 \%$ of neonates, it was fewer than five times per day. The daily frequency of urination in predominantly breastfed neonates was eight times (or more) in $55.8 \%$ of neonates and less than five times in $12.8 \%$. However, there was no significant relationship between the urination frequency and mode of feeding. ${ }^{24}$

In the present study, the serum level of sodium in infants consuming breast milk and sugar water was higher than that of exclusively breastfed infants. In another study, sodium level in infants with exclusive breastfeeding was lower than that of infants consuming the traditional supplements plus breast milk. ${ }^{25}$ Moreover, another study showed a significant relationship between the severity of weight loss and hypernatremia. ${ }^{23}$ In newborns consuming complementary sugar water, weight loss and hypernatremia may be due to reduced milk intake.

In the present study, the prevalence of renal failure was significantly higher in neonates receiving additional sugar water, compared to the exclusively breastfed group. In another study, maternal and neonatal risk factors for renal failure included inadequate emptying of breast after breastfeeding, reduced daily frequency of breastfeeding, shorter breastfeeding duration, more severe weight loss, and less frequent urination. ${ }^{26}$ Another study also showed that feeding sugar water and flixweed, besides breast milk, had a clear association with inappropriate lactation position, lack of let-down reflex, and reduced frequency or duration of breastfeeding. ${ }^{4}$ Consequently, these infants may experience weight loss and reduced urination frequency, resulting in an increase in the serum levels of sodium, urea, and creatinine and exacerbation of their problems.

In the present study, in newborns receiving sugar water plus breast milk, the platelet count was about $100,000 / \mathrm{mm}^{3}$ lower than that of breastfed infants. In another study, thrombocytopenia was reported in $41 \%$ of patients with hypernatremia, and there was a strong correlation between hypernatremia and thrombocytopenia among neonates with hypernatremic dehydration. In fact, more complications and poor prognosis were seen in patients with thrombocytopenia. ${ }^{27}$ The cause of decreased platelet count among infants is unknown in our study. Nonetheless, dehydration, hypernatremia, and azotemia in these infants may have inhibitory effects on the bone marrow or may cause a state with excessive peripheral platelet consumption.

The major limitation of this study was our inability to determine the cause and effect relationship between neonatal problems and consumption of sugar water.

\section{CONCLUSION}

The results of the present study showed that consumption of sugar water along with breast milk is associated with the lower frequency and duration of lactation, lower frequency of urination, greater weight loss, and higher serum levels of sodium, urea, and creatinine. Additionally, younger maternal age, more breast problems, and inappropriate breastfeeding position were more commonly observed in infants who received additional sugar water along with breast milk.

\section{REFERENCES}

1. WHO U, USAID A, UCDAVIS I. Indicators for assessing infant and young child feeding practices: conclusions of a consensus meeting held 6-8 November 2007 in Washington DC, USA. Geneva: World Health Organization, 2008.

2. Geneva SW. The optimal duration of exclusive breastfeeding. A systematic review. Geneva WHO, 2001.

3. Boskabadi $\mathrm{H}$, et al. The effect of traditional remedies (Camel's Thorn, Flixweed and Sugar Water) on idiopathic neonatal jaundice. Iran J Pediatr. 2011;21(3):325. 
Boskabadi H, et al. Breast milk vs milk plus sugar water

4. Boskabadi H, Bagheri S. Comparison between infants receiving traditional supplements (camel thorn, flix weed, and sugar water) and exclusively breast-fed infants. Avicenna J Phytomed. 2015; 5 (6): 479.

5. Behrman R, et al. Nelson Textbook of Pediatrics. Philadelphia: WB Saunders, 2004.

6. Stuebe AM, Bonuck K. What predicts intent to breastfeed exclusively? Breastfeeding knowledge, attitudes, and beliefs in a diverse urban population. Breastfeed Med. 2011; 6 (6): 413-20.

7. Ahmed A, et al. Complications due to breastfeeding associated hypernatremic dehydration. J Clin Neonatol. 2014; 3 (3): 153.

8. Qiu LG, et al. Infants. Asia Pac J Clin Nutr. 2007; 16 (S1): 458-61.

9. El-Gilany AH, et al. Newborn first feed and prelacteal feeds in Mansoura, Egypt. Biomed Res Int. 2014. https://doi. org $/ 10.1155 / 2014 / 258470$

10. Fikree FF, et al. Newborn care practices in low socioeconomic settlements of Karachi, Pakistan. Soc Sci Med. 2005; 60 (5): 911-21.

11. Saúde MdSSdAà. Departamento de Ações Programáticas e Estratégias. II Pesquisa de prevalência de aleitamento materno nas capitais brasileiras e Distrito Federal. Ministério da Saúde Brasília; 2009.

12. Mortazavi F, et al. Breastfeeding Practices During the First Month Postpartum and Associated factors: impact on breastfeeding survival. Iran red crescent Med J. 20: 17(4); e27814.

13. Gartner $L M$, et al. Breastfeeding and the use of human milk. Pediatrics. 2005; 115 (2): 496-506.

14. Boskabadi $\mathrm{H}$, et al. Long-term neurodevelopmental outcome of neonates with hypernatremic dehydration. Breastfeed Med. 2017; 12 (3): 163-8.

15. Giugliani ERJ, et al. Intake of water, herbal teas and nonbreast milks during the first month of life: associated factors and impact on breastfeeding duration. Early Hum Dev. 2008; 84 (5): 305-10.
16. Jalali Aria K, et al. Causes of unsuccessful exclusive breastfeeding in mother registered in Gorgan health centers. J Gorgan Univ Med Sci. 2001; 8: 81-6.

17. Boskabadi $\mathrm{H}$, et al. Risk factors of breast problems in mothers and its effects on newborns. Iran Red Crescent Med J. 2014; 16 (6).

18. Rocci E, Fernandes RAQ. Breastfeeding difficulties and influence in the early weaning. Rev Bras Enferm. 2014; 67 (1): 22-7.

19. Buckstegge AK, et al. Weaning and associated factors in children from low-income communities. Rev Odontol UNESP. 2014; 43 (3): 172-9.

20. Mohammadpour R, et al. Determination of effective factors breastfeeding duration using survival analysis. J Res Dev Nurs Midwifery 2017; 14 (2): 45-50.

21. Rasenack $R$, et al. Factors associated with the duration of breastfeeding in the Freiburg birth collective, Germany (FreiStill). Geburtshilfe Frauenheilkd. 2012; 72 (01): 64-9.

22. Martin-Calama J, et al. The effect of feeding glucose water to breastfeeding newborns on weight, body temperature, blood glucose, and breastfeeding duration. J Hum Lancet. 1997; 13 (3): 209-13.

23. Boskabadi $\mathrm{H}$, et al Significant neonatal weight loss related to idiopathic neonatal hyperbilirubinemia. Int J Pediatr. 2014; 2 (4.1): 225-31.

24. Eregie CO. Observations on urinary frequency in exclusively breastfed neonates. East Afr Med J. 1998; 75 (10): 576-8.

25. Boskabadi $\mathrm{H}$, et al. The study of the relationship between hypernatremia in neonates and mode of maternal breast feeding in hospitalized infants in Ghaem Hospital of Mashhad, Iran. IJOGI. 2014; 16 (90): 1-9. http://ijogi.mums.ac.ir/ article_2591.html

26. Boskabadi H, Mohammadi S. Evaluation of risk factors associated with breastfeeding in infants with acute renal failure. MJMS. 2015; 85 (1): 7-11.

27. Boskabadi H, Rakhshanizadeh F. Neonatal hypernatremic dehydration and thrombocytopenia: Its prevalence and relationship with prognosis. Iran J Pediatr. 2018; 28 (4). 